\title{
RoboCup@Home: Creating and Benchmarking Tomorrows Service Robot Applications
}

\author{
Tijn van der Zant \\ University of Groningen \\ The Netherlands \\ Thomas Wisspeintner \\ Fraunhofer Institute IAIS \\ Germany
}

\section{Introduction}

RoboCup and robot soccer have seen an enormous growth in the past decade, constantly widening the range of used technologies and scenarios. @Home is a new league in RoboCup with the aim to foster the development of applications in the domains of service and assistance robotics, ambient intelligence and human-robot interaction. In this book chapter, the underlying concepts of this new league are introduced. There are strong relations between the @Home league and the soccer competitions. An example is 'Natural Interaction with robotic systems'. If soccer robots are to play against humans, they should be able to understand the human environment, the 'umwelt' that humans are living in. After the introduction, we motivate the foundation of this new league by giving some philosophical background.

छิ Then, the structure and rules of the competition are explained. The league uses a set of 0 independent benchmarks that test certain abilities in the domains of human robot interaction, manipulation, navigation, localization, and human and object recognition.

들 Adapting, enhancing and integrating these benchmarks consequently over the years offer $\frac{\bar{O}}{\mathrm{O}}$ the opportunity to guide research and development toward robust, useful and applicable solutions

Not all benchmarks are predefined. An Open Challenge is provided as a platform to generate new, innovative and possibly unconventional ideas. Promising ideas are then used to adjust the road map of the league. The scope of necessary technologies is wide. Teams I $)$ have to integrate many different technologies, communicate, exchange knowledge and त्? develop multi-purpose components that can be transferred between different leagues to be $\widetilde{T}$ successful in the competition. A central goal of @Home is to provide platforms for exchange $\infty$ and standardization of science and technology in the robotics domain.

\& Section 4 points out how the @Home league is actually building on top of the technologies O developed by doing robotic soccer for the past decade. The @Home league is not only using technologies of the soccer leagues, but it is also generating new technologies. By comparing robot vs. robot soccer with @Home, and regarding the technologies we probably need to win in 2050 from humans, it becomes clear that @Home is researching technologies that can 
be transferred back to the soccer leagues once the robots start playing against humans. At the RoboCup world championships in Atlanta 2007 already the first action in this direction was demonstrated where the RoboCup trustee board played against the robot world champions of the Mid-size league. It is needless to say that the humans still played a lot better with the robots being fooled most of the time. Though it was an important step towards the big goal, it showed that the robot have no understanding of the world.

\section{Robotics: Philosophy of Mind Using a Screwdriver}

The title of this section is borrowed from I. Harvey (Harvey, 2000). He describes how the philosophical stance of the designer is reflected in the design choices being made during the creation of a robotic system. The background ideas of the designer are an important aspect of the design process. The @Home league addresses these philosophical stances of the robot designers by going into the real world where it just might be that the ideas and constructs that hold in an artificial environment (such as a soccer game) are not true and/or do not work anymore. Robotic systems that act in the real world are no longer shielded from unwanted influences. This implies also that the designers of these systems cannot hide from the problems of the real world. The idea behind robots playing soccer is to go from a static environment into a dynamic environment (Kitano et al., 1997). The idea behind robots assisting humans in a real world environment is to go from a dynamic and structured environment into a dynamic and unstructured environment that includes humans (van der Zant \& Wisspeintner, 2005).

Some of the advantages of going to the real world are that researchers can work on robots that might be able to do something useful in human society and that it is easier to demonstrate that working with robots is not only about making a great toy. These two aspects are covered in section 3.3.

One point of view is that the RoboCup is a practical investigation of the mind-body problem. Basically there are two sides on this topic. Some claim that the mind and body can be treated as separate entities, often referred to as GOFAI systems (Good Old Fashioned Artificial Intelligence) or classical Artificial Intelligence. The New Artificial Intelligence or embodied cognitive science paradigm on the other hand states that the mind, body and environment are all connected. They should not be treated as separate entities that can be studied apart from each other. For an excellent introduction on these topics, see (Pfeifer \& Scheier, 1999). If this is true then it is very important to pay close attention to the environment where the robots are functioning in. Having the real world as the environment of our robotic systems could mean that a shift in theories is necessary for the creation of artificial devices that exhibit general intelligence.

Usually the goal of the RoboCup federation is captured in the "Winning Soccer in 2050" statement. This is not the only thing that RoboCup is about. It is stated very clearly RoboCup website that "RoboCup is an international joint project to promote AI, robotics, and related fields. It is an attempt to foster AI and intelligent robotics research by providing a standard problem where wide range of technologies can be integrated and examined." Although it is clear that robotic soccer includes very important research topics, it might not address al the issues involved in the creation of robots that exhibit general intelligence. Even the best human soccer players do not always excell in general intelligence. It is therefore a 
legitimate question to ask if robotic soccer will lead us towards robots that show intelligence on a broad level.

\section{3. @Home in a Nutshell}

\subsection{The General Idea}

RoboCup@Home is a new league inside the RoboCup competitions that focuses on realworld applications and human-machine interaction with autonomous robots. The aim is to foster the development of useful, general and robust robotic technologies and applications that can assist humans in everyday life. The competition consists of a series of predefined tests, an Open Challenge and the finals where the teams are free to demonstrate new abilities and robot applications. While in the beginning necessary base abilities are being developed, tests will focus more and more on real application scenarios with a rising level of uncertainty, requiring a high grade of system integration.

\subsection{The Scenario}

At the moment the competition takes place in is a constructed living room scenario. To foster general solutions, the scenario is not standardized or pre-defined So shape, walls, floor or furniture change every time. Within a few years some of the tests should be held in the real world environment like a real supermarket where the robots have to assist humans with shopping. To foster advance in technology and to keep the competition interesting, the scenario and the tests will steadily increase in complexity.

\subsection{Social Relevance}

The applications that are being tested for should have social relevance. Through showing what robots can already do, people can see for themselves what robots could do for them. It is important to create public awareness. Robots that assist humans in every day situation are easy to relate to. If robots are to be accepted by humans they should also be appealing There are several implications with the 'social relevance' argument. One of them is that the robots should behave appropriately if they ever are to be accepted. This is called 'robotiquette' in (Dautenhahn, 2007). She argues that it is important that not only the robot is part of the research about robots, but also how humans react to them.

Another aspect is that robots should be social. Humans interact differently with each other than with non-humans, such as animals, robots and objects. Social intelligence predates object intelligence. Primate intelligence evolved in social situations, where it was important to be smarter than the other primates of the group in order to create the best chance to procreate. This is called the social brain hypothesis (Dunbar R., 2003). Even animals that do not have the possibility to manipulate objects show social intelligence. This might imply that in order to create robots that show general intelligence, it is important that researchers create robots that exhibit social intelligence, also called sociable robots (Breazeal, 2002). 


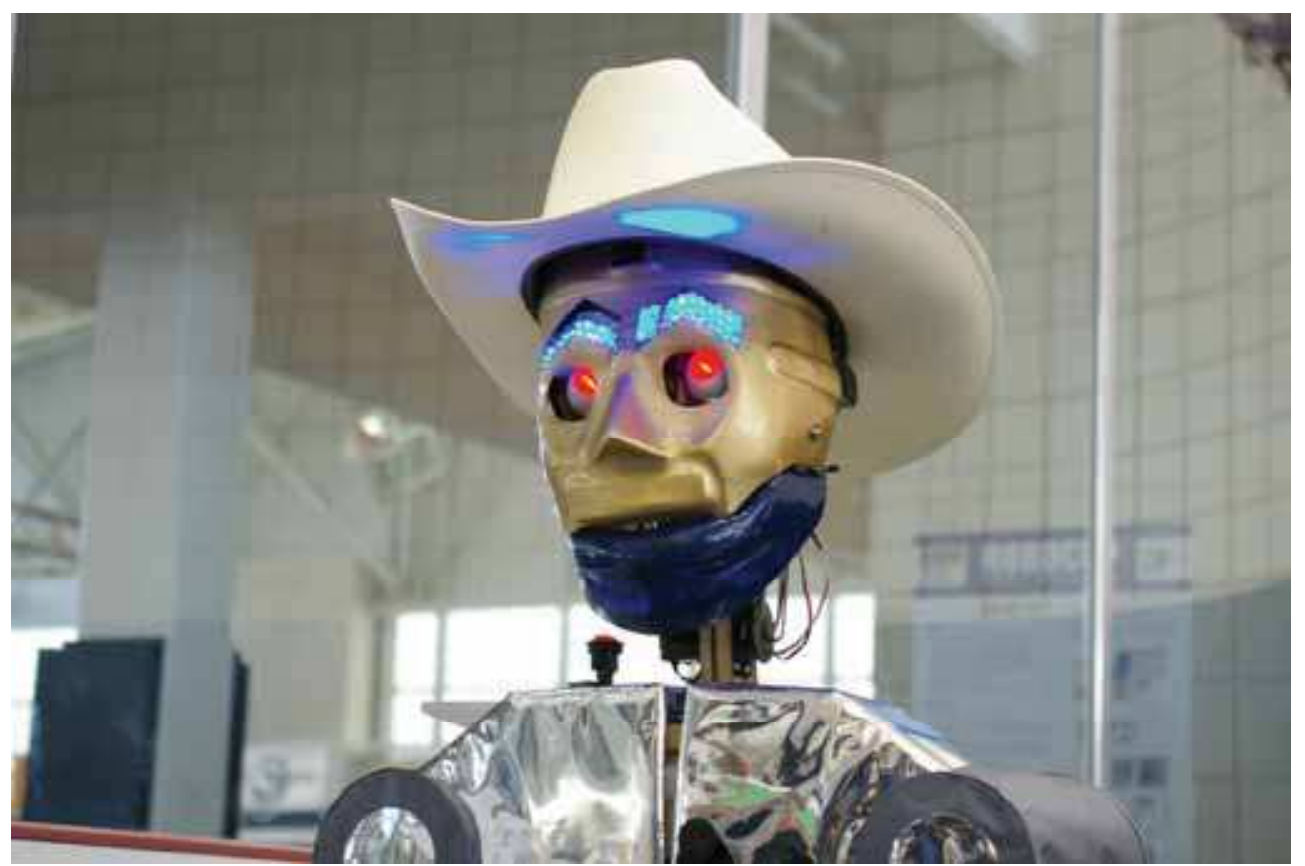

Figure 1. The @Home robot from the Pumas team (Mexico), lead by Jesus Savage, trying to convey some emotions. The first steps towards sociable robots?

\subsection{Tests}

Tests evaluate predefined base abilities which form the core of the league. Each test consists of a 'proof of concept' and a 'general applicability' phase. During the proof of concept uncertainty and complexity is limited by allowing the team modify the environment, doing the set up and the execution of a test. This ensures a low entry level for new teams. In the second phase the setting up and execution is done by external people with restrictions on the use of aiding technologies (like markers or external devices). In both cases set up time is limited to a few minutes to foster effective and simple calibration and set up procedures. For example, in the 'Follow and Guide' test, the robot has to follow a person and guide him back to the start location. The setup time is limited to a maximum of one minute including calibration on the person. The automatic calibration procedure can be started by a single push of a button or by using a voice command. In other tests the following questions are currently being addressed:

- Can a robot recognize and identify persons?

- Can it open a door?

- Can it navigate robustly in natural environments?

- Is the robot save to handle?

- Does it have an appealing appearance?

- Does it allow for cooperation with humans

- Can it communicate with other intelligent systems and humans

- Can the robot manipulate random objects? 
Does it have a basic understanding of the world?

The investigated capabilities will change over time and highly depend of the already achieved skills. The combination of predefined, independent tests and the Open Challenge, where these and new abilities should be integrated to form new application scenarios, support a gradual and iterative development. On purpose, the league does not have an ultimate goal like the soccer leagues do. Instead it functions more as a roadmap generator, with the league responding flexibly to new improvements in technology and new upcoming application.

\section{Winning in 2050 ?}

To win with soccer playing robots in 2050 implies that the robots should be humanoids and preferably androids (MacDorman \& Ishiguro, 2006), with the same or similar physical capabilities that humans posses. The needed capabilities are still far away from what is common in the present day. It is the firm believe of the authors that the @Home league is investigating also the technologies that are needed by the soccer playing robots of the future. It is very likely that a lot of the science and technology from the @Home league will be transferred to the soccer leagues once they start to play against humans.

\begin{tabular}{|l|c|c|c|}
\hline Technology/environment & $\begin{array}{c}\text { Robot-robot } \\
\text { soccer }\end{array}$ & @Home & $\begin{array}{c}\text { Human- } \\
\text { robot soccer }\end{array}$ \\
\hline Object recognition & + & + & + \\
\hline Navigation & + & + & + \\
\hline Dynamic environment & + & + & + \\
\hline Autonomy & + & + & + \\
\hline Reliability & + & + & + \\
\hline Specialized AI & - & + & + \\
\hline General AI & - & + & 0 \\
\hline Language understanding & - & + & + \\
\hline Natural human-robot interaction & 0 & + & 0 \\
\hline Reasoning capabilities & 0 & + & + \\
\hline Adaptive vision & 0 & + & + \\
\hline Adaptive behaviour & - & + & + \\
\hline Recognition of human intentions & - & + & + \\
\hline Understanding of human emotions & - & + & + \\
\hline Recognition of human behaviour & - & + & + \\
\hline Recognition of individuals & - & + & + \\
\hline Localization in unstructured environments & - & + & + \\
\hline Learning by example & - & + & 0 \\
\hline Manipulation of random objects & + & + \\
\hline
\end{tabular}

Table 1. Overview of research aspects for robot vs. robot games, @Home league and humans vs. robot games. '-' means unlikely, ' 0 ' means probably and ' + ' means very likely 


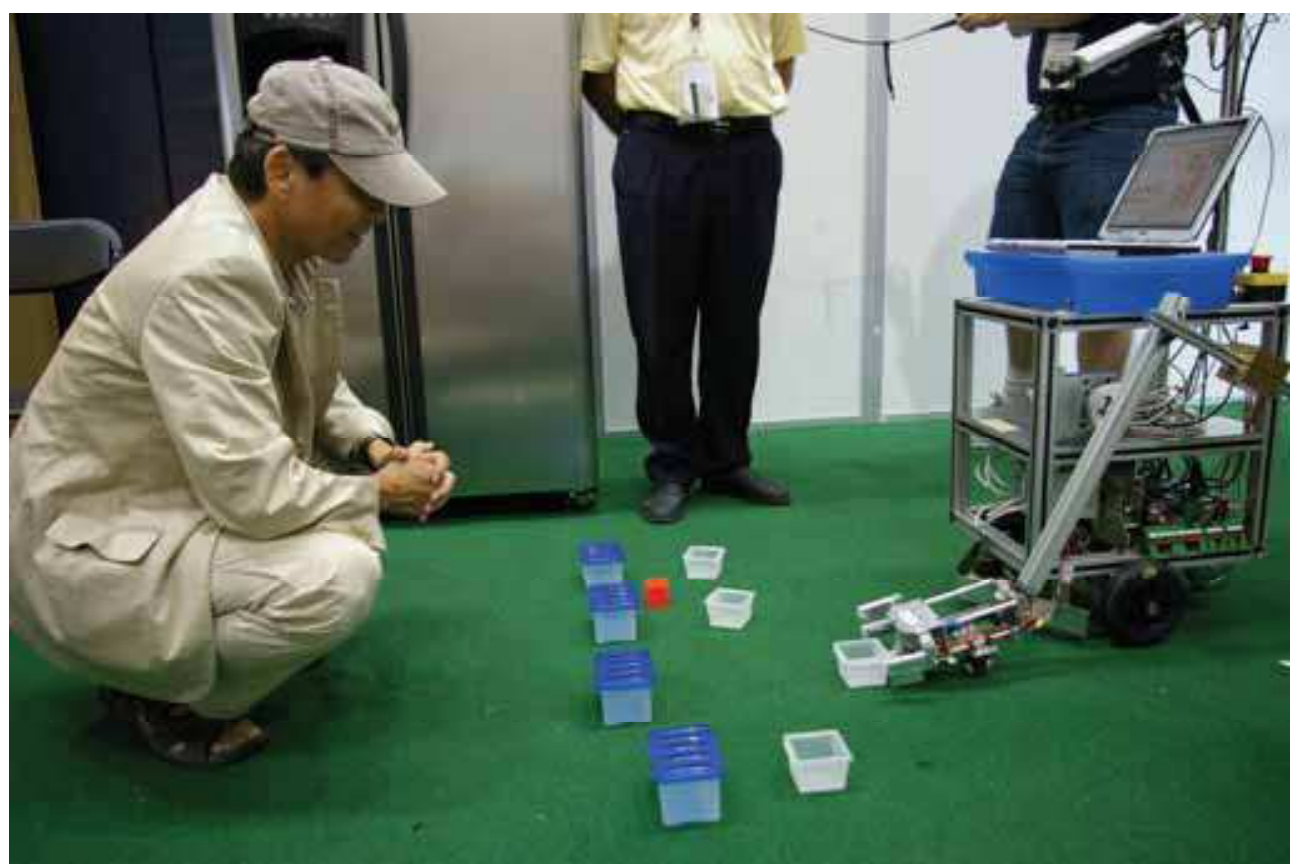

Figure 2. Human-robot interaction. In this picture the president of the RoboCup federation, Minoru Asada, is playing a game with the @Home robot from the RH2-Y team (Switzerland), lead by Jean-daniel Dessimoz

Table 1 tries to give an overview of relevant research topics and requirements for playing soccer with robots playing against robots, for the @ Home league and those that are probably required by androids winning a soccer game in 2050 .

At the moment issues such as the understanding of language or recognizing certain humans are not tackled. Issues such as the recognition of emotion are even further down the road. It is already difficult enough to recognize one's own team mates and the analysis of the behaviour of the opponent is so difficult that hardly any team is trying it at all. Also localization is not easy, especially not on large soccer fields. Could this have something to do with the environment? Localization is usually about recognizing the corner poles, the white lines and the goals. But when I, as a human, am on a soccer field then there is usually one tribune (always empty in my case) and on the other side there are often trees or a clearing. I do not have to recognize the cornet poles, or recognize the goalkeeper's face from a distance, or do complex mathematics on white lines in the grass... Instead I look if I see the tribune or the trees and I know exactly which way to dribble with the ball. Maybe it is also an idea, when one is working on a soccer robot, to take the rest of the world into account. In the first two years of the @Home competitions it became very clear how important soccer research has been and still is to be able to perform decently in the @Home league. For example, the Allemaniacs' team (Schiffer et al., 2006), the @ Home world champion in 2006 and 2007 has been participating in the mid-size league for years, and they even used a modified mid-size league robot. 


\section{Future Work}

What can be expected in the near future of the @ Home league? In the next five years the plan is to introduce cooperative tasks between humans and robot. An example would be cooking together, where the robot can get a recipe from the internet and stir a spoon around in the dough. Ambient intelligence will also come into focus. The robot should be able to interact with house hold devices and can function as the ultimate interface.

The grasping of unknown object is a task that people in the league are already working on. In 2009 we plan to have the robots go shopping in a real supermarket (not an artificial scenario). Humans can have simple conversations with robots by use of natural language and gestures. One idea is to actually involve a developmental psychologist who assesses the robot to get an estimation of the age it would have were it a human. An example is occlusion; it takes a few years before the human infant realizes that an object is not gone when it is out of sight. Quite often the robotic systems are not much better than toddlers. Since it is measurable, we will probably introduce it. It requires natural interaction and would give an indication of the amount of human intelligence it possesses. Perhaps this could be a $21^{\text {st }}$ century version of the all-too-famous Turing test.

\section{Conclusions}

RoboCup@Home is a league that has its foundations in robotic soccer. Technologies developed in soccer are being transferred to the @ Home domain and on top op these technologies @ Home might be able to give some more back. To reach the goal of winning in 2050 it will be necessary to use technologies developed in the @Home league. Since @Home focuses on general artificial intelligence in real world scenarios, theories will probably be developed that are not being developed in the soccer scenarios. Especially if the brain, body and environment are considered to be a holistic system where interactions go in all directions, the environment should also be paid attention to. Therefore the soccer leagues might also want to experiment with more than the artificial cues that are available in a soccer game.

Breazeal, C. L.(2002). Designing sociable robots, The MIT Press, ISBN 978-0262025102, Cambridge, USA, MA

Dautenhahn, K. (2007). Socially intelligent robots : dimensions of human-robot interaction, Philosohical Trans. R. Soc. B(2007) 362, pp. 679-704

Dunbar, R. I. M. (2003). The social brain: mind, language and society in evolutionary perspective. Annu. Rev. Anthropol. 32, 163-181

Harvey, I. (2000). Evolutionary Robotics : From Intelligent Robots to Artificial Life, Vol. III, Gomi, T. (Ed.), AAI Books, Ontario, Canada, 2000. pp. 207-230. ISBN 0-9698872-3-X.

Kitano H., Asada M., Kuniyoshi Y., Noda I., and Osawa E. (1995). RoboCup: The Robot World Cup Initiative, Proceedings of the IJCAI-95 Workshop on Entertainment and AI/Alife, Springer, Berlin

MacDorman, K. F. \& Ishiguro H. (2006). The uncanny advantage of using androids in cognitive and social science research, Interaction Studies 7:3, 297-337, ISSN 1572-0373

Pfeifer, R. \& Scheier C. (1999). Understanding Intelligence, The MIT Press, ISBN 0-262-16181-8, Cambridge, Massachusetts 
Schiffer, S., Ferrein, A., Lakemayer, G.(2006). Football is coming Home, Proceedings of the International Symposium of Practical Cognitive Agents and Robots, November 2006, Australia

Van der Zant, T. \& Wisspeintner, T. (2005), RoboCup X: A proposal for a league where RoboCup goes real world, Proceedings of the RoboCup 2005: Robot Soccer World Cup IX. Osaka, July 2005, Springer, Berlin 


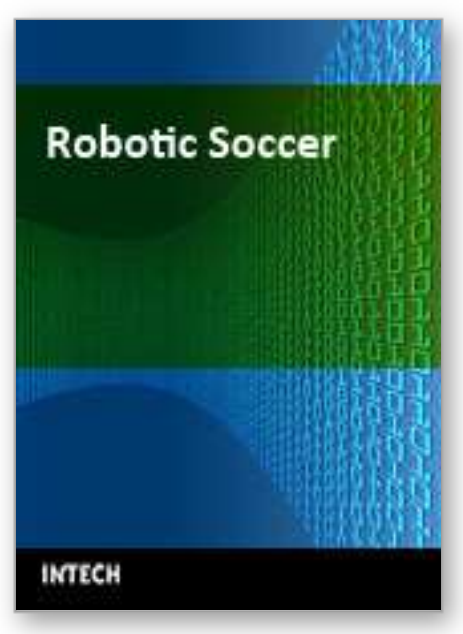

\author{
Robotic Soccer \\ Edited by Pedro Lima
}

ISBN 978-3-902613-21-9

Hard cover, 598 pages

Publisher I-Tech Education and Publishing

Published online 01, December, 2007

Published in print edition December, 2007

Many papers in the book concern advanced research on (multi-)robot subsystems, naturally motivated by the challenges posed by robot soccer, but certainly applicable to other domains: reasoning, multi-criteria decisionmaking, behavior and team coordination, cooperative perception, localization, mobility systems (namely omnidirectional wheeled motion, as well as quadruped and biped locomotion, all strongly developed within RoboCup), and even a couple of papers on a topic apparently solved before Soccer Robotics - color segmentation - but for which several new algorithms were introduced since the mid-nineties by researchers on the field, to solve dynamic illumination and fast color segmentation problems, among others. This book is certainly a small sample of the research activity on Soccer Robotics going on around the globe as you read it, but it surely covers a good deal of what has been done in the field recently, and as such it works as a valuable source for researchers interested in the involved subjects, whether they are currently "soccer roboticists" or not.

\title{
How to reference
}

In order to correctly reference this scholarly work, feel free to copy and paste the following:

Tijn van der Zant and Thomas Wisspeintner (2007). RoboCup@Home: Creating and Benchmarking Tomorrows Service Robot Applications, Robotic Soccer, Pedro Lima (Ed.), ISBN: 978-3-902613-21-9, InTech, Available from:

http://www.intechopen.com/books/robotic_soccer/robocup_home_creating_and_benchmarking_tomorrows_s ervice_robot_applications

\section{INTECH}

open science | open minds

\author{
InTech Europe \\ University Campus STeP Ri \\ Slavka Krautzeka 83/A \\ 51000 Rijeka, Croatia \\ Phone: +385 (51) 770447 \\ Fax: +385 (51) 686166 \\ www.intechopen.com
}

\author{
InTech China \\ Unit 405, Office Block, Hotel Equatorial Shanghai \\ No.65, Yan An Road (West), Shanghai, 200040, China \\ 中国上海市延安西路65号上海国际贵都大饭店办公楼405单元 \\ Phone: +86-21-62489820 \\ Fax: +86-21-62489821
}

